Revista Complutense de Historia de América

ISSN: $1132-8312$

http://dx.doi.org/10.5209/RCHA.64695

\title{
Oriente islámico, esclavitud femenina y matrimonio en el México decimonónico. Una estrategia discursiva ${ }^{1}$
}

\author{
Alejandra Palafox Menegazzi ${ }^{2}$
}

Recibido: 10 de abril de 2018 / Aceptado: 25 de mayo de 2018

Resumen. Mediante el análisis de la Crónica Parlamentaria, publicada paulatinamente por el diputado y escritor liberal Francisco Zarco, este artículo persigue comprobar cómo la contraposición discursiva a una otredad oriental permitió a los miembros del Congreso Constituyente mexicano de 1856 alcanzar determinados objetivos del programa político nacional, relativos a la libertad individual, la indisolubilidad matrimonial y el tratamiento de la tolerancia de cultos. Pone de manifiesto, además, la centralidad que el discurso orientalista tuvo entre las reacciones que los diputados protagonizaron frente un conjunto de representaciones femeninas, contrarias a la implantación del polémico artículo décimo quinto del Proyecto Constitucional, cuestionando la supuesta influencia clerical sobre estas mujeres y evidenciando otros medios de difusión de esta exotizada visión.

Palabras clave: Liberalismo; género; orientalismo; México, Siglo XIX.

[en] The Islamic East, Female Slavery and Marriage in 19th century Mexico. A discursive strategy

\begin{abstract}
By virtue of an analysis of the Parliamentary Chronicle, published gradually by the Deputy and liberal writer, Francisco Zarco, this article attempts to prove how a discursive contraposition to an Oriental Otherness allowed members of the Constituent Mexican Congress of 1856 to reach specific objectives of the national political program regarding individual liberties, the indissolubility of marriage and the treatment of religious tolerance. It shows, furthermore, the centrality of the orientalist discourse in the reactions of the congressional representatives to a series of female representations that were contrary to the approval of the controversial Article 15 of the Constitutional Project, which questioned the Church's supposed influence over these women and evidenced other means of diffusion of this exoticized vision.
\end{abstract}

Keywords: Liberalism; Gender; Orientalism; Mexico; $19^{\text {th }}$ Century.

Sumario. 1. Introducción. 2. Libertad individual, indisolubilidad matrimonial y otredad. 3. Inmoralidad, despotismo islámico y esclavitud sexual: el orientalismo en los debates en torno al polémico artículo decimoquinto. 4. El miedo al harén en las representaciones femeninas. 5. Conclusiones. 6. Referencias bibliográficas.

Cómo citar: Palafox Menegazzi, A. (2019) Oriente islámico, esclavitud femenina y matrimonio en el México decimonónico. Una estrategia discursiva, en Revista Complutense de Historia de América 45, 261-280.

\section{CONICYT. Postdoctorado 2018, nº 3180184.}

2 CONICYT. Universidad Autónoma de Chile (Chile).

E-mail: alejandra.palafox@uautonoma.cl 


\section{Introducción}

Es difícil situar y cuantificar históricamente los orígenes de la migración mediooriental $^{3}$ en México pues, si bien ésta comenzó a finales del siglo XIX, su registro oficial quedó establecido sólo a partir de 1926, ya en época post-revolucionaria ${ }^{4}$. Fue a partir de estos años, además, cuando se desarrolló una política migratoria restrictiva, reacia a la entrada de sirios, libaneses, armenios, palestinos, árabes y turcos, por considerar que, al dedicarse al comercio ínfimo y al agio, representaban una mala influencia para la nación ${ }^{5}$. Según estimaciones oficiales, entre 1882 y 1932, arribaron a México más de siete mil nativos del Levante mediterráneo, de los cuales se calcula que menos del $5 \%$ eran musulmanes ${ }^{6}$.

A pesar de su lejanía geográfica y de no haber un interés estratégico directo en la zona, la atención política y cultural hacia el Medio Oriente, además de constituir una herencia colonial, fue incrementándose en el país a lo largo del siglo XIX. Si bien no fue hasta el tardo-romanticismo que las formas orientalistas eclosionaron en la literatura y en la estética mexicana, las expediciones napoleónicas en Egipto y Siria, el acercamiento entre la Monarquía Hispánica y el Imperio Otomano, acontecimientos bélicos como la Guerra de Crimea o la edición mexicana de obras como Historia de la Turquía y El Viaje a Oriente de Alphonse Lamartine, provocaron que la temática oriental mantuviera desde inicios de la centuria una fuerte presencia en las tertulias, los cafés y las discusiones políticas, llenando las páginas de algunos de los principales periódicos de la capital ${ }^{7}$.

En los arduos debates parlamentarios que tuvieron lugar en el seno del Congreso Constituyente celebrado entre 1856 y 1857 en el Salón del Palacio Nacional de la ciudad de México, lejos de mantenerse al margen de esta cuestión, los diputados incorporaron numerosas alusiones a un lejano y exotizado Oriente, especialmente -aunque no sólo- durante las sesiones en las que se discutió la conveniencia de aprobar los artículos duodécimo y decimoquinto del proyecto constitucional, relativos respectivamente a libertad del hombre y al establecimiento de una tolerancia de cultos que favorecería una política migratoria europea ${ }^{8}$.

Estas discusiones constituyeron, además, la primera aparición del matrimonio como tema de debate en la esfera pública, al considerar algunos diputados las incon-

3 El empleo del término "Medio Oriente" se ha privilegiado aquí frente al de "Próximo Oriente" por criterios pragmáticos y geográficos, al emplazar nuestra perspectiva en territorio americano y a pesar de ser conscientes de la impronta euro-céntrica que la historia de ambos términos encierra. Para evitar confusiones, seguimos aquí la línea interpretativa trazada por el historiador Stephen Humphreys y asumimos tanto el "Medio Oriente" como el "Levante" como una extensión territorial que abarca parte del oeste sur-asiático y del norte de África y que, pese a su diversidad cultural, presenta rasgos idiosincráticos particulares, ligados a una historia común. Humphreys, 2005: XIV-XV.

Zeraoui, 2006: 12.

Bokser Liwerant, 2008: 328.

Martínez Assad, 2008: 358-359.

Martín Asuero, 2005.

8 El citado artículo duodécimo del proyecto constitucional cambió su ordenación en la Carta Magna de 1857, figurando como el Artículo Quinto. A pesar del fracaso de la propuesta sobre libertad de cultos, en los meses siguientes el gobierno se aseguró de establecer un acercamiento a las poblaciones extranjeras, reconociendo el derecho de los extranjeros a adquirir bienes inmuebles en el país, incluyendo minas. Pese a ello, hasta 1883 no se materializó legalmente el fomento de la colonización extranjera, mediante las leyes sobre enajenación, deslinde y ocupación de terrenos baldíos. 
gruencias que presentaba su naturaleza contractual en términos liberales ${ }^{9}$. Las argumentaciones de los congresistas, pese a girar alrededor de la libertad individual y religiosa, acabaron concerniendo, por tanto, aspectos centrales en la organización del sistema sexo-género a nivel federal, tales como qué papel correspondía a las mujeres en la esfera matrimonial y cuál debía de ser su posición fuera del ámbito doméstico. En este marco, además de constituir una eficiente estrategia argumentativa en términos de género, las referencias a un imaginado Oriente operaron como herramientas identitarias en términos nacionales, en un momento en el que las estructuras estatales mexicanas contrastaban con una conflictiva y divisoria diversidad interna ${ }^{10}$.

El conjunto de este tipo de alusiones quedaron enmarcadas en un "discurso orientalista", entendiendo el discurso en términos foucaultianos y por tanto, como bien señala Aäron Moszowski, como elemento que fomenta la producción tanto del saber como de "la realidad que aparentemente se describe"1". Acorde con el ya clásico estudio de Edward Said, el orientalismo refiere un "conjunto de ideas generales al que se supedita el resto del material [...] sobre 'lo oriental', como si fuera una abstracción ideal e inmutable" 12 . En las representaciones de ese lejano, desconocido y construido Oriente, que quedó limitado prácticamente al mundo árabe e islámico, los legisladores mexicanos adoptaron esta perspectiva, defendiendo sus diversos puntos de vista mediante una reiterada contraposición a una otredad oriental estática y monolítica.

El objetivo de esta estrategia, lejos de atender cuestiones relacionadas con el ajeno Oriente referido, se centró en construir y defender, mediante esta oposición discursiva, determinados modelos nacionales de orden, moral, progreso y libertad. Estos discursos sirvieron, además, para fomentar una feminidad deontológica, acorde con los principios rectores del ideal de domesticidad decimonónico. De esta manera, los oradores defendieron la situación jurídica femenina presente en el país, omitiendo su desigualdad intrínseca, como si de una realidad equitativa, justa, moderna y civilizada se tratara, a través de su contraposición a la supuesta esclavitud que las mujeres sufrían en el idealizado Oriente islámico.

Mediante el análisis de la Crónica Parlamentaria, publicada paulatinamente por el diputado y escritor liberal Francisco Zarco ${ }^{13}$ entre 1856 y 1857, en este artículo buscamos comprobar, desde una perspectiva de género, cómo el arraigo de una suerte de discurso orientalista entre la intelectualidad legislativa mexicana, mediante el ejercicio de una contraposición a una otredad oriental construida, permitió a los

9 El liberalismo hispanoamericano decimonónico, como recoge María Eugenia Claps Arenas “constituyó un gran mosaico ideológico que se movió desde las tendencias más moderadas e incluso conservadoras, hasta las más exaltadas y radicales". Claps Arenas, 2010: 57.

10 Berninger, 1974: 166-167. Paoli, 2015.

11 Moszowski, 2011: 155.

12 Said, 1990: 21. Autores posteriores, como Daniel Martin Varisco, criticaron la obra saidiana por considerar que fue fruto de una selección malintencionada del autor, dirigida a consolidar su visión homogenizante del Orientalismo. Martin Varisco, 2007. Conscientes de las críticas, consideramos pertinente retomar aquí el concepto saidiano de discurso orientalista pues, pese a su heterogeneidad, los textos analizados coadyuvaron a crear, reforzar, y consolidar un conjunto de estereotipos orientales con objeto de construir una identidad propia que operara como mecanismo de control y sujeción, también en términos de género.

13 Francisco Zarco Mateos (1829-1869) fue uno de los escritores y políticos liberales más relevantes de la historia decimonónica mexicana. Fundador del periodismo republicano, colaboró con diversas publicaciones y desde 1852 dirigió El Siglo XIX, periódico donde desde febrero de 1856 aparecieron publicadas las reseñas que el mismo Zarco redactó de las sesiones del congreso objeto de análisis en este artículo. González Oropesa, 1993: $9-20$. 
congresistas elaborar y alcanzar determinados objetivos del programa político nacional ${ }^{14}$. Nos preguntamos al respecto hasta qué punto se trató de un recurso puntual o si, por el contrario, fungió como estrategia argumentativa común entre la elite político-intelectual del país. Para ello, abordaremos algunas de las referencias esbozadas por los congresistas como método disuasorio en defensa de la libertad individual, la indisolubilidad matrimonial y el tratamiento de la tolerancia de cultos. Consideraremos, también, las reacciones de los diputados frente el conjunto de representaciones femeninas contrarias a la implantación del artículo decimoquinto y la centralidad que el discurso orientalista tuvo en este contexto, cuestionando la supuesta influencia clerical sobre estas mujeres y evidenciando otros medios de difusión de esta exotizada visión.

\section{Libertad individual, indisolubilidad matrimonial y otredad}

La formulación del que sería el artículo quinto de la carta magna acerca de la libertad individual y las contrataciones en materia laboral, educativa y religiosa abrió, el 18 de julio de 1856, un interesante debate acerca de la indisolubilidad del matrimonio en México ${ }^{15}$. A pesar de que la medida a discutir no concernía la institución matrimonial, algunos diputados como el conservador Marcelino Castañeda, o el liberal Francisco de Paula Cendejas, se apresuraron a mostrar su posición frente a lo que consideraban sería una "innovación antisocial" que daría por resultado la "destrucción de la familia y pérdida de la moral"16. Otros, como el liberal José Antonio Gamboa, defendieron la perpetuidad de la unión como medio de protección femenino. Al considerar que la vida sexual de las mujeres se limitaba a su edad reproductora, este diputado expuso que, en caso de permitirse el divorcio vincular, habría más hombres que mujeres interesados en abandonar la sociedad conyugal hasta el punto de no haber casas de asilo suficientes "para recoger a esas desgraciadas abandonadas por sus esposos" $" 17$. En consonancia con un modelo prescriptivo de mujer imperante entre las élites liberales, la sexualidad femenina fue conceptualizada por este congresista como una característica valorada en relación con su capacidad reproductiva. La vida sexual de una mujer, por tanto, refería el margen de edad en el que ésta permanecía fértil ${ }^{18}$.

Los debates parlamentarios sobre el citado artículo y la indisolubilidad matrimonial albergaron también múltiples referencias a un otro no occidental y, por ende, no

14 Consideramos la "Crónica Parlamentaria" originariamente publicada por Zarco en el periódico El Siglo XIX y que fue corregida y editada por Catalina Sierra Casasús en: Zarco, 1979.

15 Si bien el artículo ocupó el orden duodécimo en el Proyecto Constitucional, su lugar en la Constitución de 1857 fue el quinto. En el texto causante de la polémica se recogía lo siguiente: "La ley no puede autorizar ningún contrato que tenga por objeto la pérdida o el irrevocable sacrificio de la libertad del hombre, ya sea por o por causa de trabajo, de educación o de voto religioso". Zarco, 1979: 281.

16 Marcelino Castañeda. 21-VII-1856. Zarco, 1979: 282. Para la clasificación política de los congresistas en "liberales", "moderados" y "conservadores" hemos retomado las conclusiones de la investigación de Gimate-Welsh - Marín Buendía, 2011: 134-140.

17 Las palabras del congresista, como quedó transcrito por Zarco fueron las siguientes: “¿Qué sería de la mujer si, siendo su vida sexual tan limitada, hubiera de quedar abandonada por su marido en cuanto pasa de esa edad? ¿No quedaría con esto destruido el sentimiento materno, y también el reposo del hogar doméstico? Necesitaríamos entonces casas de asilo para recoger a esas desgraciadas abandonadas por sus esposos". José Antonio Gamboa, 22-VII-1856. Zarco, 1979: 286.

18 Palafox Menegazzi, 2016: 104. 
civilizado, que fueron empleadas por los congresistas como instrumento para enfatizar sus respectivas posiciones. Además de las alusiones a la población indígena del país como una suerte de pueblo homogéneo e ignorante, los habitantes de otras áreas del planeta también sufrieron el desprecio de algunos diputados por, supuestamente, mantener costumbres antagónicas con los principios de igualdad propagados por el liberalismo civilizatorio. Dentro de esta lógica discursiva, el reconocido intelectual liberal Ignacio Ramírez se mostró partidario del mantenimiento de la institución matrimonial tal y como figuraba en el derecho mexicano, por considerar que en ella se reconocía la igualdad entre hombres y mujeres, mostrando, sin embargo, su preocupación frente a la inoperancia de las autoridades judiciales frente a casos de sevicia marital, es decir, frente a actos de "excesiva crueldad", según la normativa penal vigente en la época ${ }^{19}$. "Esto es tan vergonzoso en un pueblo civilizado", sostenía al respecto, "que en pueblos casi bárbaros como en el Indostán, por ejemplo, hay una ley que dice: 'No pegues a la mujer ni con una rosa'" 20.

La referencia a poblaciones exóticas y lejanas para denunciar la violencia sufrida por las esposas en México sirvió a éste y otros diputados para silenciar la formal situación de desigualdad entre hombres y mujeres ratificada por la institución matrimonial pues no hay que olvidar que, a mediados del siglo XIX, el matrimonio, además de seguir estando sujeto al derecho privado colonial, restringía los derechos femeninos en la esfera pública. Sólo las mujeres solteras o viudas mayores de 25 años que estuviesen exentas del dominio o la potestad paternal o marital podía administrar libremente sus bienes, otorgar contratos y obligarse como principales sin licencia o permiso de nadie, con los mismos derechos que los hombres. Por el contrario, las mujeres casadas para poder "comprar, vender, trocar, ceder, transigir, donar, tomar y dar prestado, comparecer en juicio y hacer otros contratos y casicontratos" debían contar con la autorización marital, al considerarse que con sus actos afectaban al ente superior de la sociedad conyugal ${ }^{21}$.

Ante esta situación, el moderado Pedro Escudero y Echanove fue el único en denunciar que el matrimonio suponía un atentado en contra del principio de libertad de las mujeres, sosteniendo la mujer al casarse sacrificaba realmente su libertad pues no podía contratar, adquirir ni heredar sin consentimiento de su marido, por lo que en el

19 El divorcio eclesiástico, figura que permitía la separación no vincular de los cónyuges, fue el único divorcio vigente en México hasta la promulgación de la Ley de Matrimonio Civil de 23 de julio de1859. Durante los años de debates parlamentarios que comentamos en este artículo, si bien el derecho canónico reconocía la crueldad marital como motivo válido para la obtención del divorcio por parte de la esposa, como demostró la investigadora Silvia Marina Arrom, "el castigo físico moderado" fue una costumbre socialmente aceptada. La crueldad contemplada por la ley, por tanto, fue concebida como "sevicia", es decir, como exceso de crueldad, según se recoge en las principales obras de jurisprudencia de la época, como el "Diccionario" de Joaquín Escriche. Arrom, 1988: 255 y 315; Escriche, 1876: 1147. Desde 1859, la separación de los cónyuges -siempre temporal y sin disolución del vínculo matrimonial- quedó en manos de la justicia civil. Esta reforma legal conllevó la sanción de esta costumbre social, reconociendo explícitamente que la crueldad, sólo cuando fuese "excesiva", podría constituir motivo de divorcio. La Ley de Matrimonio Civil del 23 de julio de 1859, sancionada en el Código Civil de 1870, en su artícuo 21 , sección $5^{\text {a }}$, además de dificultar el acceso al divorcio no vincular de aquellas mujeres víctimas de maltrato, reconoció explícitamente la obligación de las esposas de obedecer, agradar, asistir, consolar, aconsejar y venerar a sus respectivos maridos. Ley de matrimonio civil. 23-VII-1859. Dublán - Lozano, 1877: 693.

20 Ignacio Ramírez. 10-VII-1856. Zarco, 1979: 249.

21 Las leyes coloniales, aun vigentes, que regulaban estas limitaciones eran las Siete Partidas y las Leyes de Toro, en concreto: Partida III, 2, 5; Partida IV, 23,2; Partida VI, 3, 2; Partida VI, 16, 4 y de la Ley 54 a la 61 en las Leyes de Toro. De la Pascua, 2010: 355. 
matrimonio el hombre era todo y la mujer no era más que un objeto ${ }^{22}$. Las palabras de este diputado, además de no contar con el respaldo del congreso, levantaron una fuerte oposición entre varios congresistas, quienes defendieron el statu quo de la sujeción femenina como algo acorde con los principios civilizatorios y liberales. El presidente del congreso y abogado, el liberal Ponciano Arriaga, sostuvo al respecto que la mujer al casarse no sacrificaba su libertad y que llamarla "cosa" en "una asamblea democrática y cristiana" implicaba prorrumpir en una blasfemia ${ }^{23}$. Según Arriaga, la civilización cristiana había permitido liberar a la mujer -"la más hermosa y la más noble mitad del género humano"-, quien, si sacrificaba algo de su libertad, no lo hacía por imposición sino por voluntad propia y para la consecución de un fin superior como el amor, la maternidad o el bien de la sociedad y el género humano. Recordando los principios clásicos del contractualismo político liberal, Arriaga sostenía que, de la misma manera que los liberales sacrificaban parte de su libertad "por la civilización y por la humanidad", al someterse a un gobierno y sus leyes, las mujeres debían supeditarse a la voluntad marital en la esfera matrimonial ${ }^{24}$.

Dentro de una lógica lineal, acorde con los ideales ilustrados de evolución y progreso, este diputado sostuvo que a mayor grado de civilización de un pueblo se correspondía un mayor enaltecimiento de la mujer y de sus derechos, y que el desarrollo que había caracterizado a la historia mexicana no permitía comparar esta nación con otras donde todavía existían atrasados modelos conyugales como la poligamia. El discurso orientalista se presentó de nuevo como una herramienta útil para la defensa del mantenimiento de la situación jurídica femenina:

A medida que los pueblos adelantan en la civilización, enaltecen a la mujer y reconocen sus derechos. [...] Si la mujer es nada, si la mujer es cosa, ¿podrá llevar el sr. Escudero a su casa siete u ocho mujeres como quien lleva siete u ocho sillas? [...] No, porque la mujer no es cosa, porque la mujer tiene derechos que protege la ley, porque la mujer es igual al hombre, porque debe ser respetada, porque al lado de la esposa no pueden entrar al hogar doméstico las concubinas ${ }^{25}$.

Si bien, en atención a las leyes mexicanas, las relaciones sexuales extra-matrimoniales no estaban permitidas, tanto en la jurisprudencia como en la práctica judicial, tan sólo las infidelidades femeninas recibían el calificativo de "adúlteras" y ameritaban castigo penal ${ }^{26}$. Consciente de la tolerancia social e institucional que, en la práctica, existía frente a este tipo de transgresiones masculinas, Ponciano Arriaga evitó recordar que los hombres casados debían fidelidad a sus esposas, haciendo referencia a la exótica y demonizada figura del harén. La animadversión frente a algunos indígenas del país, considerados como culturas atrasadas, por otro lado, coadyuvó al congresista a reconocer sutil e implícitamente que aunque las mujeres casadas no fueran objetos, era lícito, paradójicamente, que fungieran como propiedad de sus maridos. Como quedó recogido en la Crónica de Zarco:

\footnotetext{
22 Literalmente este diputado sostuvo: "En el matrimonio el hombre es todo, la mujer no es nada, la mujer es cosa". Pedro Escudero y Echanove, 22-VII-1856. Zarco, 1979: 287.

Ponciano Arriaga. 22-VII-1856. Zarco, 1979: 288.

Ibídem; Palafox Menegazzi, 2016: 102.

Ponciano Arriaga. 22-VII-1856. Zarco, 1979: 288.

Palafox Menegazzi, 2016: 11-13.
} 
El orador [...] observa que en los pueblos privados de la luz de la revelación, en los pueblos que no conocen la Escritura, el matrimonio es indisoluble, y aun entre los salvajes, que no están muy lejos [...] aun entre los salvajes, el matrimonio es también perpetuo e indisoluble, respetado, existe la familia y, en punto a celos, al derecho exclusivo de poseer a la esposa hay una gran escrupulosidad y no se transige en lo más mínimo ${ }^{27}$.

En armonía con lo expuesto por Arriaga, el diputado veracruzano José María Mata, también de tendencia liberal, sostuvo que considerar a la mujer como esclava significaba "retroceder veinte siglos en la carrera de la civilización, [...] cerrar los ojos a la luz del cristianismo [...] y olvidar que la misión de Cristo fue la emancipación del género humano y, por consiguiente, la de la mujer"28.

La compleja relación entre libertad individual y religión, que se convertiría en un tema central en las discusiones acerca del proyecto del artículo decimoquinto sobre la tolerancia de cultos, llamó el interés de algunos diputados ya durante estas sesiones anteriores. El propio Castañeda se mostraba contrario a que las leyes interfirieran en la relación de cada individuo con Dios por considerar que ello atentaba directamente contra la libertad del hombre. Frente a esta posición, el liberal Cendejas, no dudó en recurrir a la otredad oriental para defender la regulación legal de los votos religiosos, argumentando que, en caso contrario, el Estado debería permitir que, "como en algunos pueblos de Oriente", hubiese hombres que, "creyendo servir a Dios", rehusaran el alimento y tomasen yerbas "para trastornar su razón"29. Dirigir la mirada hacia una lejana y desdibujada tierra oriental, esta vez sin la impronta islámica, a pesar de ser una acción sustentada en generalizaciones, constituía una estrategia de distracción sencilla, dado el lógico y extendido desconocimiento de las dinámicas religiosas orientales de parte de los congresistas.

\section{Inmoralidad, despotismo islámico y esclavitud sexual: el orientalismo en los debates en torno al polémico artículo decimoquinto}

El 28 de julio de 1856 iniciaron los debates en torno al artículo decimoquinto del proyecto constitucional, relativo a la implantación de la tolerancia de cultos y defendido por quienes esperaban que la permisividad religiosa sirviera como estímulo para la llegada de población europea y protestante al país ${ }^{30}$.

Días antes del inicio del debate, la programada discusión del artículo ya suscitó fuertes controversias y una gran polémica dentro y fuera de la asamblea, donde las argumentaciones de los congresistas eran seguidas con ávido interés tanto por los espectadores que aguardaban en las galerías como por quienes leían o escuchaban la lectura de los periódicos. La prensa, segmentada ideológicamente, se hizo eco y

\footnotetext{
Ponciano Arriaga. 22-VII-1856. Zarco, 1979: 288.

José María Mata. 22-VII-1856. Zarco, 1979: 289.

Francisco de P. Cendejas. 22-VII-1856. Zarco, 1979: 284.

30 En el texto a debate se recogía lo siguiente: "No se expedirá en la República ninguna ley ni orden de autoridad que prohíba o impida el ejercicio de ningún culto religioso; pero, habiendo sido la religión exclusiva del pueblo mexicano la católica, apostólica, romana, el Congreso de la Unión cuidará, por medio de leyes justas y prudentes, de protegerla en cuanto no se perjudiquen los intereses del pueblo ni los derechos de la soberanía nacional". Zarco, 1979: 321.
} 
participó activamente en los acalorados debates acerca de esta cuestión religiosa, llegando e involucrando, así, a diversos sectores de la sociedad mexicana ${ }^{31}$. Además de un creciente público, al Congreso no tardaron en llegar peticiones de hombres y mujeres que, en su mayoría, solicitaban a los representantes de la nación que no permitieran la implantación de la tolerancia de cultos en la República.

Una vez iniciados los debates, tanto las referencias a la situación matrimonial femenina como las argumentaciones de carácter orientalista se multiplicaron. Partidarios y detractores del artículo decimoquinto parecieron haber encontrado sus mejores armas discursivas en las reflexiones en torno a las mujeres y al mundo islámicooriental. Pese a que aquellos que se mantuvieron contrarios a permitir cultos no católicos en México mencionaron el islam como una potencial amenaza del orden social, la familia y las propias mujeres, los defensores de la tolerancia también recurrieron a esta religión y a los pueblos de mayoría musulmana para construir sus reflexiones.

La recién concluida Guerra de Crimea, librada durante casi tres años entre el Imperio Ruso y el Imperio Otomano y referenciada por los congresistas como "Guerra de Oriente", a pesar de la evidente neutralidad mexicana en el conflicto, sirvió a partidarios y detractores de la tolerancia de cultos como temática instrumental a la hora de defender sus respectivas posiciones. De esta manera, algunos como el diputado liberal por San Luis Potosí, Francisco Villalobos, lo hicieron como medio de apoyo a la aprobación del artículo decimoquinto, recordando que había sido la intolerancia rusa la causante de la guerra. Otros, sin embargo, aprovecharon la contienda para manifestar su arraigada animadversión hacia el mundo musulmán, justificando así el haber simpatizado con Imperio zarista. De esta manera, el moderado diputado y ministro de Exteriores, Luis de la Rosa, después de evidenciar el escándalo que la introducción del "mahometismo" [sic] causaría en la Unión Americana, afirmó "en nombre del Gobierno" que "las simpatías que se notaron durante la última guerra en favor de la Rusia se derivaban, en parte, de que este imperio combatía contra los que profesan la inmoral religión mahometana" [sic $]^{32}$.

Firme impulsor del artículo decimoquinto y confundiendo la libertad de cultos -que era lo que se debatía- con la libertad de conciencia, el liberal José María Mata no dudó en recordar que incluso Turquía, "esa nación fanática que por tantos años ha permanecido segregada de la comunión europea" había proclamado "el gran principio de libertad de conciencia"33. "El cristiano no es ya considerado allí como perro ni como esclavo", sostuvo al respecto, "el cristiano ha sido elevado a la dignidad de hombre. Goza no sólo de la libertad de adorar a Dios según sus creencias, sino que ha sido elevado al goce de los derechos civiles, a la participación de todos los beneficios sociales" 34 .

En efecto, el Imperio Otomano, aludido aquí de forma sinecdóquica, estaba concluyendo un proceso político conocido como Tanzimat, vocablo turco que significaba "regulación y organización", y bajo el que se desarrolló un proceso modernizador de corte occidental, en términos militares y organizativos, basado en una burocratización estatal, una mayor tolerancia frente a la diversidad religiosa, la sustitución de

31 Los debates parlamentarios fueron seguidos de cerca por la prensa del país, los liberales impulsores de las reformas, sus detractores políticos nacionales y diversos observadores extranjeros. Savage, 2011: 141-142. Según Antonio Martínez Báez, se trató del mayor debate público de la Historia Mexicana. Martínez Báez, 1959: 5.

32 Luis de la Rosa. 22-VII-1856. Zarco, 1979: 242.

33 José María Mata. 29-VII-1856. Zarco, 1979: 326.

34 Ibídem. 
los departamentos gubernamentales por ministerios y la reestructuración del ejército $^{35}$. Pese a ello, para algunos diputados liberales como Guillermo Langlois, Turquía seguía figurando dentro de la categoría de "bárbaro despotismo oriental" en contraposición a "los países libres" en donde se protegía la inocencia y el llamado "vicio del pueblo" era reprimido por sí o por sus representantes ${ }^{36}$.

No permitir la tolerancia de cultos en México, según la lógica de sus partidarios, suponía un retroceso en términos civilizatorios e históricos, una vuelta a "los tiempos de Felipe II, a los tiempos de Mahoma", como afirmó Rafael Jáquez, diputado liberal por el Estado de Guerrero, entendiendo por ello "los tiempos en que el convencimiento entraba en los hombres con la hoguera, con el cuchillo"37. De nuevo aquí, las alusiones al profeta sirvieron para reforzar los argumentos del orador, quien, recurriendo a una construcción binaria, equiparó el pasado inquisidor de la colonia con los orígenes de la religión musulmana, oponiendo de forma maniquea ambas imágenes al progreso civilizatorio esperado para el país.

Con objeto de ensalzar la tolerancia de cultos como una característica propia de los pueblos civilizados, el liberal Francisco Villalobos, trató de explicar en qué consistía su ideal de libertad mediante diversos contraejemplos de culturas contrarias al permisivo "espíritu del siglo", lo que, de nuevo, incluyó intentos de desprestigiar a la religión musulmana, como se recoge en la narración de la siguiente anécdota:

Otro hecho aún demasiado reciente: un agente del Gobierno inglés litigaba ante un magistrado musulmán, por no sé qué querella habida entre ambos. El primero salió gritando por las calles que la religión de Mahoma peligraba. El populacho se arrojó sobre el empleado británico, queriendo despedazarle; pero pudo éste refugiarse en su casa, donde se fortificó. La turba fanática puso fuego al edificio, y algunas horas después se encontró entre las ruinas un grupo de cadáveres abrazados entre sí y abrasados por el fuego, y entre ellos el de una mujer que arrojaba del seno maternal un feto desfigurado por las llamas... ¡Éstos son los efectos de la intolerancia! ${ }^{38}$.

Frente a lo expuesto por algunos diputados defensores de la tolerancia de cultos, gran parte del pueblo llano y de las mujeres de los diversos sectores sociales, parecían compartir el miedo a que se expandieran por México las costumbres y prácticas sexuales atribuidas a los musulmanes, como era el concubinato, causando la disolución de la familia y el orden social. "El pueblo no quiere la tolerancia. [...] ¿No se nos ha

35 Los movimientos separatistas en la Península Balcánica, así como las intervenciones de las potencias europeas en los asuntos internos del gobierno otomano, motivaron este movimiento reformista. Como recuerda Margalit Bejarano, la reforma "otorgó a los ciudadanos de todas las religiones igualdad de derechos, dentro de sus respectivos millet -musulmán, judío, armenio o griego-. El impuesto directo (jiziyia) que pagaban los no musulmanes fue abolido, pero fue sustituido por el pago de un rescate para liberarse del servicio militar. Las reformas anularon el estado inferior de los dimmíes, pero no cambiaron su diferencia legal y social”. Bejarano, 2008: 43-44.

36 Guillermo Langlois. 18-VIII-1856. Zarco, 1979: 498. Estas calificaciones surgieron en el marco del debate sobre implantación en el país del juicio por jurados, en el que Langlois defendió el modelo jurídico deseado como la materialización de la "libertad", a través de su oposición a supuestas realidades opresoras, entre las que, además "Turquía”, figuraron la antigua metrópoli española, y "Rusia”. Si bien el jurado popular para delitos comunes no fue establecido en la capital mexicana hasta 1869, los debates en torno a esta figura jurídica se dieron desde las primeras décadas de independencia política del país. Véase al respecto Speckman Guerra, 2005.

37 Rafael Jáquez. 30-VII-1856. Zarco, 1979: 357.

38 Francisco Villalobos. 2-VIII-1856. Zarco, 1979: 399. 
dicho, no hemos oído que queremos la santificación del concubinato [...]?”, sostenía, al respecto, el intelectual liberal Guillermo Prieto ${ }^{39}$. "Se afecta creer que, como la ley no prohíbe ningún culto, tendremos el islamismo y el harem, y el enjambre de concubinas, y la pérdida de las herencias, y la ilegitimidad de los hijos, y otras muchas cosas que invente la imaginación de los abogados", añadía al respecto José María Mata.

A pesar de que algunos de los defensores del artículo decimoquinto trataron de desligarse de estas afirmaciones, atribuyéndolas a la combinación entre la inventiva de algunos conservadores y una supuesta ignorancia femenina y popular, sus detractores no dudaron en mostrar su firme adhesión a estos argumentos. El matrimonio a mediados del siglo XIX constituía el pilar básico de la estructura familiar y, por ende, del orden social deseado para el país. Su carácter sacramental hacía de este contrato una realidad indisoluble de los principios católicos que lo determinaban. Según estos congresistas, por tanto, en un momento en el que diversas fuerzas civiles trataban de concluir el proceso de escisión entre las instituciones estatales y las eclesiásticas, relegando a estas últimas a un papel secundario en la política nacional, erradicar la base católica que simbólicamente sostenía a la sociedad o permitir la entrada de otras creencias, y en especial del islam, socavaría irremediablemente los cimientos del orden establecido.

De entre todos, el representante del Estado de México, el conservador Mariano Arizcorreta, fue quien se atrevió a mostrar con mayor determinación su animadversión hacia la libertad de cultos, sosteniendo que con ésta se permitiría el ejercicio del "culto mahometano [ $\mathrm{sic}]^{\prime 40}$, lo que legitimaría la práctica de la poligamia y el establecimiento de harems. "Así como el católico pone en ejercicio su culto contrayendo matrimonio" sostenía el diputado, “[...] así también el mahometano, al poner su serrallo, pone en ejercicio por un acto externo su culto, obedeciendo un precepto del Alcorán" $" 41$. Al permitirse las conversiones al islam, Arizcorreta evidenciaba los peligros que los primeros hijos de los nuevos musulmanes correrían en México, al verse abocados a compartir sus derechos con sus "nuevos hermanos habidos en las nuevas concubinas", lo que, en palabras del congresista, conllevaría la destrucción del derecho de sucesión y, en consecuencia, el "desquiciamiento social"42. Por otro lado, según el diputado, el dueño del harén tenía "derecho de vida y muerte" sobre sus concubinas, por lo que la introducción "del culto mahometano [sic] restablecería la esclavitud femenina en el país, esclavizando así a "la mitad más hermosa del género humano"43.

Parece importante resaltar que, salvo una excepción, a pesar de la fuerte intensidad que tuvieron las discusiones sobre el artículo decimoquinto, sus protagonistas no cuestionaron en ningún momento que el ejercicio de la religión musulmana en el mundo conllevara la implantación del harem, entendido como una suerte de esclavitud sexual femenina ${ }^{44}$. Esta asociación parecía tener un valor axiomático entre políticos e intelectuales, divididos al respecto sólo a la hora de determinar el grado

\footnotetext{
Guillermo Prieto. 30-VII-1856. Zarco, 1979: 351.

Mariano Arizcorreta. 30-VII-1856. Zarco, 1979: 367.

Ibídem.

Ibídem.

Ibídem.

44 La posesión de harenes era una práctica poco extendida en los países de mayoría musulmana, entre otros motivos, por la falta de recursos materiales suficientes para mantener a todas las esposas. Una visión general sobre la esclavitud femenina desde la época medieval y hasta el siglo XIX puede consultarse en la reciente obra: Martín Casares - Delaigue, 2017. Si bien no es nuestro objeto de estudio, debemos recordar que la esclavitud sexual femenina a mediados del siglo XIX no estaba limitada al mundo islámico e, incluso en las cercanas colonias caribeñas conservadas por la antigua metrópoli española en América, su presencia era extraordinaria.
} 
de amenaza que el islam podía representar para México. El liberal y firme defensor de la tolerancia de cultos, Juan de Dios Arias, por ejemplo, si bien consideró infundados los temores que preconizaban que la libertad comportaría la llegada del islam en el país, en una evidente referencia a esta religión, también se mostró partidario de complementar el debatido artículo, incluyendo una cláusula que exceptuara aquellos cultos cuyas prácticas fueran contrarias a la moral o a las garantías que concedía la Constitución ${ }^{45}$. Esta medida fue secundada también por el liberal Villalobos, quien sostuvo que las religiones que autorizaran la poligamia o la esclavitud de las mujeres deberían prohibirse, no ya por su calidad de culto sino por atentar contra lo que se consideraba que eran los derechos naturales de las personas.

Si atendemos a la Crónica redactada por Francisco Zarco, tan sólo este autor cuestionó que todos los musulmanes -referenciados siempre de forma sinecdóquica como "turcos" expuesto por el diputado Arizcorreta, pues si la presencia de "un turco en cualquier corte de Europa" era algo extraordinario, el orador no sabía de dónde se esperaba que "brotaran" turcos en México ${ }^{47}$. Pese a ello, en el improbable caso de que un "torrente de turcos" se avecindara en la República y trajera consigo sus respectivos harems, sus esposas dejarían de ser esclavas en el momento de llegar al país, pudiendo "decir a su bajá 'beso a usted la mano' y dejarlo sólo" 48 . Efectivamente, la legislación vigente en México no autorizaba el ejercicio de la esclavitud y contravenía la poligamia, a pesar de tolerar en la práctica que mujeres recurrieran a la protección material de varones a cambio de favores sexuales, auspiciando por tanto, una efectiva dependencia femenina hacia los varones ${ }^{49}$.

Ante la llegada de hombres solteros, según Zarco, la oposición de "paisanas católicas, civilizadas y libres" ante el "matrimonio a la mahometana", es decir, ante la instauración de harenes en México, sería suficiente para frenar su establecimiento. Como quiso aclarar el congresista, los defensores de la tolerancia de cultos no buscaban destruir la institución de la familia sino que, por el contrario, defendían la "dignidad de la mujer" "50. Entender a qué se refería este liberal al hablar de la dignidad femenina resulta complicado, pues ésta quedó simplemente definida mediante su contraposición a la esclavitud islámica. Debemos considerar, además, que la Era de Reforma en la que se enmarca la celebración del Congreso representó un momento histórico crucial en la reformulación de los derechos femeninos en general y de la situación jurídica de las esposas en particular. Lejos de impulsar el reconocimiento de una igualdad de género en el ámbito público y privado, por el contrario, la tendencia imperante entre los reformistas liberales mexicanos, acorde con las medidas que se estaban aprobando en otros países de Europa y América, fue la de reforzar la autoridad patriarcal dentro del ámbito familiar, supeditando la voluntad de las esposas a los designios maritales, lo que culminó con la Ley de Matrimonio Civil expedida en $1859^{51}$.

\footnotetext{
45 Juan de Dios Arias. 1-VIII-1856. Zarco, 1979: 390.

46 "Turco" era una referencia genérica, extendida en América Latina para aludir a los habitantes del Imperio Otomano, ya fueran maroníes, drusos, musulmanes, griegos, armenios o judíos. Bejarano, 2008: 40.

47 Francisco Zarco. 4-VIII-1856. Zarco, 1979: 410.

48 Ibídem.

49 Véanse al respecto los siguientes trabajos: Palafox Menegazzi, 2013 y 2016.

50 Francisco Zarco. 4-VIII-1856. Zarco, 1979: 410.

51 Mijangos y González, 2016: 106; Staples, 2001.
} 
La religión católica no peligraba frente a la tolerancia de cultos pues, como afirmaba el liberal Castillo Velasco, la conservarían y defenderían "nuestras madres y nuestras esposas, nuestras hijas y nuestras hermanas; [...] el bello sexo, esa encantadora mitad del género humano que tanta influencia ejerce en los pueblos y en los hombres" $" 52$. Dentro de esta lógica, las mujeres mexicanas fueron concebidas como seres secundarios, valorados en función de su belleza y su relación de parentesco con un sujeto varón, además de como guardianas de la tradición $\mathrm{y}$, por ende, del catolicismo.

Pese a estas puntuales referencias, conscientes de los sentimientos de rechazo que provocaba el exotizado islam, quienes abogaron por la instauración del artículo decimoquinto trataron, en su mayor parte, de omitir alusiones a la religión de las mezquitas, resaltando mediante diversos contraejemplos los beneficios que la llegada de población protestante supondría para el desarrollo económico y el bienestar de la nación.

\section{El miedo al harén en las representaciones femeninas}

La polémica suscitada en torno a la implantación de la tolerancia de cultos en el país sobrepasó, como ya hemos comentado, las paredes del Palacio Nacional, llegando e inquietando a varios sectores de la sociedad mexicana. Pronto arribaron al Congreso representaciones firmadas por diversos colectivos, principalmente eclesiásticos, en las que se solicitaba encarecidamente el rechazo del artículo decimoquinto del proyecto constitucional. De entre todas estas peticiones, como han puesto de manifiesto Susana Sosensky y Evelyne Sánchez, las representaciones firmadas por señoras de varias ciudades fueron aquellas que suscitaron mayor interés entre los congresistas y no era de extrañar, pues se trataba de la primera intervención femenina colectiva de ese calibre que tenía lugar en el hasta el momento vetado espacio político mexicano $^{53}$. En algunas de estas peticiones, sus suscriptoras mostraron un estilo directo, fruto de una consolidada conciencia política, aprovechando, incluso, para denunciar sutilmente la situación de supeditación a la autoridad varonil a la que, ya fuera por motivos familiares o de mera subsistencia, estaban condenadas en México ${ }^{54}$.

Si bien, por la forma de las peticiones y el reconocimiento de algunas de las firmantes, éstas parecían pertenecer a los estratos más acomodados de la sociedad, debemos considerar que el nivel cultural de la mayor parte de estas mujeres, según apuntan las investigaciones desarrolladas hasta el momento, dependía de la formación recibida en el ámbito privado ${ }^{55}$. Esta situación sirvió como argumento, tanto a

52 José María Castillo Velasco. 6-VIII-1856. Zarco, 1979: 418.

53 Si bien ya en 1849 un grupo de mujeres de Orizaba había enviado al Congreso una representación solicitando que no se aprobara la libertad de cultos en el país, el volumen de peticiones femeninas que arribaron en 1856 fue inaudito. Para la ciudad de México, por ejemplo, participaron formalmente en la solicitud 1047 mujeres. Sosenski, 2004: 57-59; Sánchez, 2013.

54 Las señoras firmantes de la ciudad de Morelia afirmaban al respecto: "Nuestra condición de vivir siempre subordinadas; en la infancia y adolescencia a nuestros padres; en la juventud y madurez a nuestros maridos o a las personas de quienes dependemos por la subsistencia, por nuestro estado o por nuestros negocios. Una mujer del todo independiente es muy rara. Viviendo siempre subordinadas, mayor necesidad tenemos de la justicia y bondad de quienes dependemos". Martínez Báez, 1959: 26.

55 En época independiente seguía siendo común la asistencia de las niñas de familias pudientes, menores de doce años, a las llamadas "Escuelas de Amiga", centros religiosos donde aprendían a leer y desempeñar labores do- 
la prensa, como a los congresistas liberales, para cuestionar la autoría de estos documentos pues, al contener disertaciones de carácter político, histórico o teológico, parecían ser obra de influyentes miembros del clero e ideólogos conservadores.

Las reacciones de los diputados liberales, lejos de considerar las denuncias que sobre su propia posición social presentaron algunas de estas mujeres, en general, estuvieron dirigidas a deslegitimar la incursión femenina en el espacio público, bien restando crédito a la misma o bien tachándola de inadecuada tanto por la naturaleza como por la formación de sus protagonistas. Por su parte, los diputados conservadores trataron de omitir el carácter político de las representaciones, interpretándolas como muestras naturales de la defensa femenina del espacio doméstico de la fami1 lia ${ }^{56}$.

Las resistencias a la libertad de culto provenían de "cinco millones de indios y las mujeres", tachados ambos de "ignorantes" por el ministro moderado Lafragua quien, hablando sólo desde su cargo de diputado, consideraba, sin embargo, que, ante esta situación, la instalación de otras confesiones en el país causaría irremediables e indeseados desórdenes sociales. De la misma manera, los liberales Ponciano Arriaga, Isidoro Olvera, Ignacio Ramírez y Francisco Zarco, así como el conservador Prisciliano Díaz González, entre otros, no dudaron en mostrar su rechazo por lo que consideraban era el resultado de la excesiva influencia que el clero ejercía sobre el "bello sexo" 57 .

Si bien no fue un argumento central en las disertaciones femeninas, algunas de estas mujeres manifestaron también su miedo a que el islam se expandiera por México. Al respecto, por ejemplo, las suscriptoras morelianas alegaron que en el "mahometanismo" [sic] la mujer era "tan esclava como en la gentilidad" pero vivía "más humillada en la subordinación, y más brutalmente ajada en sus preciosas dotes del pudor y de la sensibilidad" ${ }^{58}$.

mésticas, rara vez aquí se las enseñaba a escribir. Gonzalbo Aizpuru, 2004: 133. Tras las distintas reformas educativas que, en materia administrativa, centralistas y federalistas trataron, sin éxito, de implementar en el país desde los primeros años de su independencia, en 1856, bajo el gobierno provisional de Ignacio Comonfort, se desarrolló el proyecto de creación de la primera escuela oficial de educación secundaria o superior para niñas de la ciudad de México, dependiente de los fondos de la Instrucción Pública. Arrom, 1988: 36. Esta medida contó con un Plan de Estudios en el que figuraban, entre otras, las asignaturas de religión y moral cristiana y social"; gramática castellana; poesía y literatura; música, dibujo y nociones de pintura; bordado; elaboración floral y jardinería; historia; geografía física y política, resaltando el aprendizaje de los principios del sistema republicano democrático; aritmética; idiomas; higiene; economía y medicina domésticas y educación física. Decreto 3-IV1856. Se establece en México un colegio de educación secundaria para niñas. Dublán - Lozano, 1877: 145-146. Pese a la falta de aplicación de esta normativa, la misma evidenció el interés por parte de un sector político por modificar la formación de las mujeres en consonancia con un ideal de ciudadanía diferenciado genéricamente.

56 A mediados del siglo XIX el ideal de mujer como madre, esposa, hija y hermana, garante de la moral familiar y defensora de la religión católica fue promovido políticamente, en especial desde los sectores conservadores. Pani, 1996: 75-77. La relegación al ámbito de lo privado por parte de este colectivo, provocó que los conservadores nunca emplearan estas representaciones como recurso para defender una mayor participación femenina en la esfera política, pese a servirse de ella para alcanzar objetivos concretos, como el rechazo de la tolerancia de cultos. Sánchez, 2013: 6.

57 Así lo exponía el Doctor Isidoro Olvera, diputado del Estado de México y secretario del Congreso "La cuestión no es teológica ni dogmática, sino puramente social. Las resistencias vienen del clero, y, si hay representaciones de algunas señoras, debe considerarse que en este asunto el bello sexo no es más que órgano del clero". Isidoro Olvera. 1-VIII-1856. Zarco, 1979: 392. Al respecto, Prisciliano Díaz González afirmaba: “¿Hemos de esperar lo que sobre estas cuestiones piensan las mujeres y sus confesores?”. Prisciliano Díaz González. 4-VIII-1856. Zarco, 1979: 411.

58 Martínez Báez, 1959: 27. 
Este tipo de inquietudes, pese a ser secundarias y estar extendidas también, como hemos visto, entre algunos diputados, fueron aprovechadas por Francisco Zarco, quien centró su atención en ellas para contestar con burla y descrédito a sus autoras, además de atribuir la responsabilidad de tales invenciones al clero:

No encontrando el clero bastante apoyo en los hombres, lo ha ido a buscar en las mujeres [...] haciéndoles creer que la religión estaba en peligro, contándoles que íbamos a [...] establecer la poligamia, a disolver el matrimonio (Risas) ¡Pobres señoras! Con razón se alarmaron. No quisieron ser abandonadas por sus maridos ni vivir en el enjambre de las nuevas esposas, ni ser inmoladas en la piedra de los sacrificios, ni que sus hijas fueran presas de mahometanos $[\mathrm{sic}]^{59}$.

¿A qué se debía la preocupación de estas mujeres de que la posible propagación en México del islam conllevara la sustitución de la familia tradicional por un sistema de esclavitud materializado en el harén y la poligamia? ¿Fue fruto de una exclusiva influencia clerical, como afirmaban algunos congresistas o, por el contrario, estuvo relacionada con una imagen compartida y difundida por distintos sectores sociopolíticos?

No buscamos aquí cuestionar la probable influencia que familiares conservadores y miembros del clero pudieron ejercer en la motivación y organización de estas suscriptoras. Sin embargo, nos parece oportuno señalar otras posibles vías de fomento orientalista, promotoras de una exotizada, demonizada y potencialmente peligrosa imagen del considerado Oriente islámico.

Al pertenecer a los sectores medios y altos de la sociedad mexicana, podemos afirmar que las señoras firmantes fueron potenciales lectoras de las proliferantes y periódicas publicaciones escritas por hombres y dirigidas a mujeres que afloraron y lograron consolidarse en el país entre 1840 y $1855^{60}$. Además de entretener, el objetivo de esta prensa femenina, en la que miembros de la intelectualidad liberal -incluido más de un congresista- tuvieron una participación extraordinaria, fue también el de educar dentro de los cánones civilizatorios auspiciados por sus editores, promoviendo un ideal de mujer capaz de desempeñar con acierto las tareas de madre y esposa de ciudadanos ${ }^{61}$.

De esta manera, en la capital del país revistas como El Calendario de las Señoritas Mexicanas, el Presente Amistoso Dedicado a las Señoritas Mexicanas o La Semana de las Señoritas Mexicanas, entre otras, desempeñaron un importante papel pedagógico, dirigido a consolidar un moderno ideal de domesticidad.

Entre sus páginas, además de consejos de moda y belleza, instrucciones de costura, cocina o botánica, partituras, poemas, cuentos y novelas, se encontraban contenidos de geografía e historia natural con una fuerte carga moralizante. En estas narraciones, hombres experimentados, aventureros y conocedores de los rincones más recónditos del globo explicaban a sus urbanitas lectoras los encantos y los peligros que escondían algunos parajes y culturas. Mediante descripciones de lugares lejanos y exóticos, a través de una labor didascálica, aparentemente dirigida a "ha-

59 Francisco Zarco. 29-VII-1856. Zarco, 1979: 336.

60 Infante, 2005: 183-194; Vega y Ortega 2010; Hernández Carballido - Hernández Téllez, 2010: 97-124.

${ }_{61}$ Tanto Guillermo Prieto como el mismo Francisco Zarco, por ejemplo, dedicaron diversas composiciones al Presente Amistoso. Dedicado a las señoritas mexicanas. Guillermo Prieto, por su parte, colaboró también con La Semana de las Señoritas Mexicanas. 
cer penetrar por todas las clases del bello sexo conocimientos generales y positivos acerca de todas las ciencias" y difundir "un anantial de inocente recreo y sólida instrucción" ${ }^{2}$, algunas de estas lecturas coadyuvaron a ofrecer la homogeneizante y distorsionada imagen del mundo árabe y oriental que parecía imperar entre la élite político-intelectual del país.

Al tiempo en el que se promovía un ideal de feminidad confinado al ámbito privado del hogar, relatos sobre mujeres "orientales" enclaustradas en harenes mostraban una terrible imagen de sujeción y esclavitud, que contrastaba con la aparente libertad que gozaban las esposas mexicanas. Así, el recurso a la poligamia de los denominados "mahometanos" se convirtió desde los primeros años en un ejercicio común por parte de quienes querían ganarse la atención de estas lectoras, lo que coadyuvaría a explicar la familiaridad de las mujeres de los sectores acomodados con esta exótica y vilipendiada imagen.

"Que en nuestra patria afortunadamente está prohibida la poligamia hasta por la santa religión [...] y aunque deseara yo no fuera así, a mí de nada me valdría supuesto que aun a los mahometanos [sic] les es permitido tener nada más de aquellas mujeres que pueden mantener". De esta manera se refería al islam con tono jocoso en 1841 Manuel Milcheltorena, general y colaborador del Semanario de las Señoritas Mexicanas, publicación editada por Vicente García Torres ${ }^{63}$. Si bien, como en este caso, algunas alusiones al, en apariencia, homogéneo mundo musulmán, podían servir de guiño humorístico, el desprecio y la animadversión marcaron la tónica de la mayor parte de estas referencias.

$\mathrm{Al}$ respecto, por ejemplo, en otra temprana publicación, continuadora en el tiempo del Semanario de las Señoritas y también bajo la edición de Vicente García Torres, el Panorama de las Señoritas Mexicanas, en el artículo de 1842 "Viajes. Quince días en Palestina", se recogían parte de las hazañas vividas por el intrépido escritor estadounidense George Robinson por los territorios orientales de Siria y Palestina ${ }^{64}$. Además de recoger detalladas descripciones sobre la historia, la geografía y la arquitectura de los lugares recorridos, en este artículo también se hacía a las mujeres conocedoras de las distintas culturas y costumbres de los dos tercios de los musulmanes que conformaban la población de Jerusalén, afirmando sobre los mismos que: "a semejanza de lo que sucede en todas las ciudades puramente religiosas, danse a conocer los mahometanos [sic] por su intolerancia y fanatismo y acerca de este punto aconsejo a todo viajero que obre con suma cautela, respetando todas sus creencias y preocupaciones" ${ }^{\prime 5}$. Esta visión contrastaba frontalmente con las benévolas alusiones a la población judía, a quien se describía como un pueblo oprimido, condenado a vivir esclavo y extranjero sobre un suelo que legítimamente le pertenecía ${ }^{66}$. Acerca de las relaciones entre hombres y mujeres, Robinson afirmaba sobre los judíos que tenían una mayor "libertad de costumbres entre los dos sexos" pese a lo que las mujeres tampoco salían de casa sin usar un velo formado por un trozo de muselina tirado sobre la cabeza que caía por su espalda hasta la cintura, similar pero más corto que el usado por las "mujeres turcas" pues sólo las mujeres de "mala

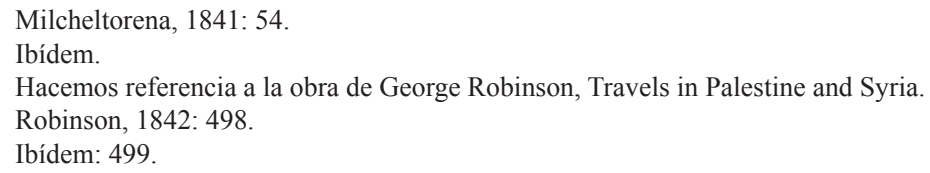


vida" no acostumbraban a portar esta indumentaria en este territorio, aludido bajo la categoría de "Oriente" 67.

Las alusiones a las mujeres "orientales" como estrategia pedagógica siguieron estando muy presentes en este tipo de publicaciones durante los años cercanos a la celebración del Congreso Constituyente. En esta dirección, en el año de 1852, La Semana de las Señoritas Mexicanas recogía esta curiosa y anónima descripción sobre las supuestamente desdichadas y seductoras "mujeres egipcias":

La suerte de las mujeres egipcias no es tan feliz como la de los hombres: condenadas a la esclavitud, no tienen ninguna influencia en los negocios públicos; su imperio se limita al interior de las paredes del harem. Confinadas al seno de sus familias, no se extiende el círculo de su vida a otra cosa más que a las ocupaciones domésticas, siendo la educación de sus hijos su primer deber, su más ardiente deseo es tener muchos porque la fecundidad es la que les da alguna consideración pública $^{68}$.

Sobre su sensualidad, este mismo artículo aseguraba que en ninguna parte desplegaban las mujeres "todos los encantos de su sexo como en el Oriente"69. Las egipcias, en especial, pese a ocultarse de la mirada del público bajo un velo cuando acudían a los baños, extendían su coquetería "hasta en sus calzoncillos, que son en verano de muselina bordada y en invierno de tisú de oro y plata"70.

Belleza, lujos y sometimiento esclavista al patriarca fueron los atributos que mejor definieron a las mujeres "orientales" descritas en estas publicaciones, elementos que, como hemos comentado, fueron centrales en las alusiones pronunciadas por los representantes de la nación durante los intensos debates que ocuparon las sesiones del Congreso Constituyente y que fueron también, aunque minoritariamente, empleados como argumentos en algunas de las representaciones femeninas a las que hemos tenido acceso.

\section{Conclusiones}

Como hemos querido demostrar en este artículo, la equiparación del islam con el fanatismo y la esclavitud femenina fue empleada como eficaz recurso de distracción y argumentación por los congresistas de distinta orientación política. Las referencias a la otredad islámica quedaron englobadas dentro de una homogenizante construcción cultural de corte orientalista, que sobrepasaba los criterios religiosos y parecía haber sido completamente asimilada por el conjunto de los representantes de la nación. Si bien es cierto que fueron los detractores del polémico artículo decimoquinto quienes se afanaron en mayor medida por presentar las terribles consecuencias que la implantación de la religión musulmana tendría en México, el reduccionismo orientalista empleado por estos oradores apenas fue discutido por sus oponentes.

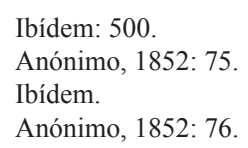


Más allá de tratarse de una mera cuestión religiosa, además, las referencias al islam formaron parte de la asimilación y reproducción de una exotizada y homogenizante construcción cultural, que englobaba distintas poblaciones cuya lejanía y desconocimiento sirvieron como útil instrumento para definir el proyecto identitario y civilizatorio deseado para México. Su empleo sobrepasó las cuestiones estrictamente relacionadas con la tolerancia de cultos o con los pueblos de Oriente Medio, fungiendo como útil instrumento retórico entre los distintos oradores. En relación con el ideal de feminidad deontológica que trató de conformarse dentro del marco político reformista, el empleo de estos estereotipos, en términos de género, reformuló los mecanismos discursivos de sujeción a través de un ideal civilizatorio identificado con un supuestamente benévolo estado liberal mexicano, construido mediante su oposición a una otredad cultural opresiva, violenta, despótica y cruel.

Diputados de distinta orientación ideológica parecían haber encontrado en el concebido como Oriente islámico la antítesis adecuada para defender sus respectivas posiciones acerca de materias concretas, sin necesidad de profundizar en sus argumentos, amparándose en los complejos y abstractos conceptos de libertad, moralidad y orden, y definiendo los mismos mediante este supuesto antagonismo oriental ${ }^{71}$. De esta manera, partiendo de la aceptación de una superioridad cultural de la propia civilización, en términos ético-morales, ésta se construyó discursivamente a través de la negación. Lo propio, es decir, lo civilizado, pasó a ser lo no salvaje, lo no despótico y, por ende, lo no oriental.

Por último, podemos afirmar que, al gozar de una excepcional influencia y gran repercusión social, -pues, salvo puntuales sesiones celebradas a puerta cerrada, las intervenciones parlamentarias se produjeron en actos públicos, fueron presenciados por una gran afluencia de vecinos de distinta extracción socioeconómica y seguidos con gran interés por la prensa nacional-, los debates analizados operaron como importantes productores y difusores del Orientalismo entre la población mexicana.

\section{Referencias bibliográficas}

Anónimo. "Mujeres Egipcias". La Semana de las Señoritas Mexicanas, vol. 1 (1852), 75 77.

Arrom, Silvia M. Las mujeres de la ciudad de México, 1790-1857. Madrid: Siglo XXI, 1988.

Bejarano, Margalit. "Los turcos en Iberoamérica: el legado del millet". En Árabes y judíos en Iberoamérica. Similitudes, diferencias y tensiones, coordinado por Rein, Raanan. Sevilla: Fundación Tres Culturas del Mediterráneo, Colección Ánfora, 2008, $39-48$.

Berninger Dieter, George. La inmigración en México (1821-1857). México D.F.: Sepsetentas, 1974.

Bokser Liwerant, Judit. "Identidades colectivas y esfera pública: judíos y libaneses en México". En Árabes y judios en Iberoamérica. Similitudes, diferencias y tensiones, coordinado por Rein, Raanan. Sevilla: Fundación Tres Culturas del Mediterráneo, Colección Ánfora, 2008, 321-358.

71 Como ya puso de manifiesto el historiador de las ideas, Elías José Palti, retomando a su vez la aserción de Reinhart Koselleck, sólo lo que no tiene historia puede definirse. Los conceptos al tener una naturaleza histórica, son siempre polisémicos. Palti, 2005. 
Claps Arenas, María Eugenia. "Liberalismo moderado y liberalismo exaltado en España y en México". En El liberalismo, la creación de la ciudadanía y los estados nacionales occidentales en el espacio atlántico (1787-1880), editado por Pérez Herrero, Pedro - Simón Ruiz, Inmaculada. Bucaramanga: Universidad Industrial de Santander, 2010, 55-82.

De la Pascua, Anastasio. Febrero Mejicano, o sea la Librería de Jueces, abogados y escribanos que, refundida, ordenada bajo nuevo método, adicionada con varios tratados y con el título de Febrero Novísimo dio a luz D. Eugenio de Tapia. Nuevamente adicionada con otros diversos tratados y las disposiciones del Derecho de Indias y del Patrio, por el Lic. Anastasio de la Pascua. México: Suprema Corte de Justicia de la Nación, 2010.

Dublán, Manuel - Lozano, José María (coomps.). Legislación mexicana o colección completa de las disposiciones legislativas expedidas desde la independencia de la República, tomo VIII. México: Imprenta del comercio, 1877, 145-146.

Escriche, Joaquín. Diccionario razonado de legislación civil, penal, comercial y forense: o sea resumen de leyes, usos, prácticas y costumbres. Ciudad de México: Oficina de Galván, 1876.

Gimate-Welsh, Adrián - Marín Buendía, María Jazmín. “Obstrucción, cabildeo y coaliciones en la Constitución de 1857. El asunto de la libertad de creencias". En Estrategia y práctica parlamentaria en un congreso plural, editado por López Flores, Raúl. México: Senado de la República Mexicana, 2011, 117-140.

Gonzalbo Aizpuru, Pilar. "Las mujeres novohispanas y las contradicciones de una sociedad patriarcal”. En Las mujeres en la construcción de las sociedades iberoamericanas, coordinado por Gonzalbo Aizpuru, Pilar - Ares Queija, Berta. Sevilla, México: CSIC, Escuela de Estudios Hispano-Americanos, COLMEX, Centro de Estudios Históricos, 2004, 121 140.

González Oropesa, Manuel. El siglo XIX de Francisco Zarco y su pensamiento constitucional. México: UNAM, 1993.

Hernández Carballido, Elvira - Hernández Téllez, Josefina. "El nosotros en la historia del periodismo y las mujeres mexicanas". En El nosotros desde nuestra mirada, coordinado por García Meza, Norma. México: Universidad Michoacana de San Nicolás de Hidalgo Universidad Veracruzana, 2010, 97-124.

Humphreys, Stephen. Between Memory and Desire: The Middle East in a Troubled Age. Santa Bárbara: California, University of California Press, 2005.

Infante Vargas, Lucrecia. "De lectoras y redactoras: las publicaciones "femeninas" en México durante el siglo XIX". En La república de las letras. Asomos a la cultura escrita del México decimonónico, coordinado por Belem Clark de Lara y Elisa Guerra. México: UNAM, 2005, 183-194.

Ley de matrimonio civil. 23-VII-1859. Dublán, Manuel - Lozano, José María (coomps.). Legislación mexicana o colección completa de las disposiciones legislativas expedidas desde la independencia de la República, tomo VIII. México: Imprenta del comercio, 1877, 691-695.

Martín Asuero, Pablo. "El viaje a Oriente de Lamartine, su traducción al español e influencia en autores hispánicos". Tonos. Revista electrónica de estudios filológicos, n 9 (2005). Disponible en https://www.um.es/tonosdigital/znum9/estudios/lamartineespa\%F1ol. htm

Martín Casares, Aurelia - Delaigue, María Cristina. Cautivas y esclavas: el tráfico humano en el Mediterráneo. Granada: Universidad de Granada, 2017.

Martin Varisco, Daniel. Reading Orientalism: Said and the Unsaid. Seattle: University of Washington Press, 2007. 
Martínez Assad, Carlos. "Libaneses cristianos, judíos y musulmanes en México". En Árabes y judios en Iberoamérica. Similitudes, diferencias y tensiones, coordinado por Raanan, Rein. Sevilla: Fundación Tres Culturas del Mediterráneo, Colección Ánfora, 2008, 357-390.

Martínez Báez, Antonio. Representaciones sobre la tolerancia religiosa. México: Colección el Siglo XXI, 1959.

Mijangos y González, Pablo. “¿Secularización o reforma? Los orígenes religiosos del matrimonio civil en México". Hispania Sacra, no 137 (2016), 105-117.

Milcheltorena, Manuel. "Cronología. Remitido". Semanario de las Señoritas Mexicanas. Educación científica, moral y literaria del bello sexo, vol. II (1841), 54-56.

Moszowski, Aäron. "La carga teórica de la mirada antropológica: el gesto "orientalista" en el México desconocido de Carl Lumholtz”. Ludus Vitalis, vol. 19 (2011), 153-169.

Palafox Menegazzi, Alejandra. "Justicia, regulación sexual y feminidad en la ciudad de México (1827-1870)". Trashumante. Revista Americana de Historia Social, n 2 (2013), 8-30.

- "Cumplir o resistir. Mujeres y delitos sexuales en la ciudad de México". Tesis Doctoral, Universidad de Granada, 2016.

Palti, Elías José. "La modernidad como problema. (El esquema "de la tradición a la modernidad" y la dislocación de los modelos teleológicos)". Modernidades. La historia en diálogo con otras disciplinas, $\mathrm{n}^{\mathrm{o}} 1$ (2005). Disponible en http://www.ffyh.unc.edu.ar/archivos/ modernidades_a/I/Revista\%20e-Modernidades.htm

Pani, Erika. "Una ventana sobre la sociedad decimonónica: los periódicos católicos (18451857)". Secuencia, no 36 (1996), 67-88. DOI: 10.18234/secuencia.v0i36.550

Paoli, Francisco José. La Guerra de Castas en Yucatán. Mérida: Editorial Dante, 2015.

Robinson, George. Travels in Palestine and Syria. Londres: Henry Colburn, 1837.

— "Viajes. Quince días en Palestina". Panorama de las Señoritas Mexicanas, (1842), 495 503.

Said, Edward W. Orientalismo. Madrid: Libertarias, Al Quibla Ensayo, 1990.

Sánchez, Evelyne. "La incursión pionera de mujeres en el espacio público. Su participación en la Asamblea Constitucional de 1856 en México". En Revolucionarias fueron todas, coordinado por Tirado Villegas, Gloria. Puebla: BUAP, Fomento Editorial, 2013, 11-29.

Savage, Mónica, "Cultura católica y modernidad liberal", En La cruz del maíz. Política, religión e identidad en México: entre la crisis colonial y la crisis de la modernidad, coordinado por Campos Goenaga, María Isabel - De Giuseppe, Massimo. México: Conacyt, ENAH-INAH, Conaculta, 2011, 133-162.

Semanario de las Señoritas Mexicanas. Educación cientifica, moral y literaria del bello sexo, vol. II. México: Vicente G. Torres, 1841.

Sosenski, Susana. "Asomándose a la política: Representaciones femeninas contra la tolerancia de cultos en México, 1856". Tzintzun: Revista de Estudios Históricos, no 40 (2004), 51-76.

Speckman Guerra, Elisa. "El jurado popular para delitos comunes: leyes, ideas y prácticas (1869-1929)". En Historia de la Justicia en México, siglos XIX y XX. México: Suprema Corte de Justicia de la Nación, 2005, 743-787.

Staples, Anne. "El matrimonio civil y la epístola de Melchor Ocampo, 1859”. En Familias iberoamericanas. Historia, identidad y conflictos, coordinado por Gonzalbo Aizpuru, Pilar. México: El Colegio de México, 2001, 217-229.

Vega y Ortega Baez, Rodrigo A. "Moral científica para el "bello sexo" en la prensa mexicana para mujeres (1840-1855)". Nuevo Mundo Mundos Nuevos (2010). Disponible en http:// nuevomundo.revues.org/60082. DOI: 10.4000/nuevomundo.60082 
Zarco, Francisco. Congreso Extraordinario Constituyente. 1856-1857. México: Secretaría de Gobernación, 1979.

Zeraoui, Zidane. "La inmigración árabe en México: integración nacional e identidad comunitaria". Contra Relatos desde el Sur. Apuntes sobre Africa y Medio Oriente, $\mathrm{n}^{\mathrm{o}} 3$ (2006): $11-32$. 